\title{
Systemic Diseases in Dakar (Senegal): Spectrum, Epidemiological Aspect and Diagnostic Time-Limit
}

\author{
B. S. Kane ${ }^{1 *}$, M. Niasse ${ }^{2}$, A. A. Ndiaye ${ }^{3}$, A. C. Ndao', B. Djiba1, N. D. Diack ${ }^{4}$, B. C. Fall ${ }^{1}$, M. A. Ndour ${ }^{1}$,

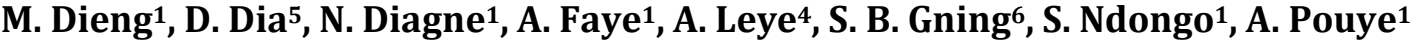 \\ ${ }^{1}$ Department of Internal Medicine, Le Dantec Hospital/Cheikh Anta DIOP University, Dakar, Senegal \\ ${ }^{2}$ Department of Rheumatology, Le Dantec Hospital/Cheikh Anta DIOP University, Dakar, Senegal \\ ${ }^{3}$ Epidemiology Unit/University of Bambey, Bambey, Senegal \\ ${ }^{4}$ Department of Internal Medicine, Pikine Hospital/Cheikh Anta DIOP University, Dakar, Senegal \\ ${ }^{5}$ Department of Internal Medicine, Grand Yoff Hospital/Cheikh Anta DIOP University, Dakar, Senegal \\ ${ }^{6}$ Department of Internal Medicine, Principal Hospital Dakar, Senegal \\ Email: ^baidykane@gmail.com
}

How to cite this paper: Kane, B.S., Niasse, M., Ndiaye, A.A., Ndao, A.C., Djiba, B., Diack, N.D., Fall, B.C., Ndour, M.A., Dieng, M., Dia, D., Diagne, N., Faye, A., Leye, A., Gning, S.B., Ndongo, S. and Pouye, A. (2018) Systemic Diseases in Dakar (Senegal): Spectrum, Epidemiological Aspect and Diagnostic Time-Limit. Open Journal of Internal Medicine, 8, 196-206. https://doi.org/ 10.4236/ojim.2018.83019

Received: August 22, 2018

Accepted: September 22, 2018

Published: September 25, 2018

Copyright (c) 2018 by authors and Scientific Research Publishing Inc. This work is licensed under the Creative Commons Attribution International License (CC BY 4.0).

http://creativecommons.org/licenses/by/4.0/ (c) (i) Open Access

\begin{abstract}
Introduction: Systemic diseases have been the subject of few studies in the African literature and have probably been under-estimated. The objective of our study was to specify their spectrum, their epidemiological aspects and diagnostic delay in Internal Medicine Departments of Dakar (Senegal). Material and Method: It was a multicentric retrospective and descriptive study regarding all systemic diseases during 119 months from 1st January 2005 to 30 November 2014 in 5 hospital centers down Dakar. Systemic diseases were retained according to their international consensus criteria. Results: During the studying period, 726 patients were included with 632 women and 94 men (sex ratio of 0.14 ). The average age was 43.76 years. Inflammatory rheumatoid family history was noted in $10.06 \%$ of cases. Rheumatoid arthritis (RA) was the predominant affection, recorded on 564 patients, isolated or associated with other systemic diseases. It was followed in a decreasing order, in the systemic auto-immune diseases sub-groupe, by systemic lupus (56 cases), Sjögren's syndrome (32 cases), Systemic Sclerosis (26 cases), Idiopathic inflammatory myopathies (21 cases), Undifferentiated connective tissue diseases (20 cases), Anti Phospholipid's syndrome (6 cases) and Mixed connective tissue disease (6 cases). A diagnosis of systemic vasculitis was recorded in 19 patients. The other systemic affections were represented by systemic sarcoidosis (8 cases), Adult-onset Still's disease (03 cases), amyloidosis (02 cases) and 02 cases of systemic syndrome associated to immunodeficiency. The mean diagnostic delay duration before the diagnostic was 3.46 years. Conclu-
\end{abstract}


sion: Systemic diseases in internal medicine are characterized by their diversity, the clear predominance of RA, and significant diagnostic delay.

\section{Keywords}

Connective Tissue Disease, Rheumatoid Arthritis, Systemic Vasculitis, Sarcoidosis, Adult-Onset Still's Disease, Africa South of the Sahara

\section{Introduction}

Systemic diseases represent a heterogeneous group of diffuse auto-immune and/or auto-inflammatory diseases and syndromes, meaning that usually touches many organs [1].

The first studies have concluded for the rarity of these affections in Africa [2]. However, the frequency of the systemic auto-immune diseases was likely to be under-estimated in Africa [3]. Indeed, In Africa, south of the Sahara, these affections are not a concern due to priority areas such as infectious and tropical diseases [4].

In our region, studies of inflammatory arthritis and autoimmune diseases have been reported.

Forty-two (42) cases on connective tissue diseases were reported during 5 years at Ouagadougou [5]. In this study, systemic sclerosis predominated, followed up by lupus disease [5]. In Togo and Abidjan, it was about respectively 84 and 44 patients, with RA as predominant affection [2] [6]. A more recent series in Togo helped to identify 626 cases of inflammatory rheumatism and connective tissue diseases in a period of 16 years [7].

We found it necessary to conduct a multicentric study about systemic disease in our country.

The aim of our study was to point out these diseases, the spectrum, their epidemiological aspects and the diagnostic delay in Internal Medicine Department of Dakar (Senegal) universities hospitals.

\section{Method of Study}

\subsection{Type of Study}

It was a retrospective and observational study carried out from $1^{\text {st }}$ January 2005 to 30th November 2014. It was carried out on all patient medical records received at external consultation or admitted for a systemic disease in the 5 Internal Medicine Units of Dakar Hospitals.

\subsection{Population of Study}

\section{1) Inclusion Criterias}

Were included all patients medical records diagnosed for affections named below, according to the international criterias as follow: 
- Rheumatoid Arthritis (RA) according to American College of Rheumatology (ACR) criteria modified by Liao [8];

- Systemic lupus erythematosus according to ACR criteria in 1997 [9];

- Sjögren's syndrome according to American-European Criteria in 2002 [10];

- Systemic Sclerosis according to ACR criteria 2013 [11];

- Idiopathic Inflammatory Myopathies according to ENMC criteria for Polymyositis (PM) and Dermatomyositis (DM) and the criteria proposed by Troyanov for overlap myositis [12] [13];

- Mixed connective tissue disease according to Alarcon Segovia's criteria [14];

- Adult-onset Still's disease according to Fautrel's criteria [15];

- Systemic vasculitis was classified according to the nomenclature Chapel Hill 2012, the different ACR criteria 1990 for granulomatosis with polyangeitis (GPA, ex Wegener), Takayasu arteritis, Periarteritis nodosa (PAN) and international criteria 2013 for Behçet's disease [16] [17] [18] [19] [20];

- Anti-phospholipid antibody syndrome (APS) according to revised criteria (2006) of APS classification [9];

- Undifferentiated Connective tissue diseases were retained, only when the explorations wereeffective (immunological, histological) and by applying the criteria indicated by Danieli et al. [21];

- Systemic Sarcoidosis was retained before:

- Evocative clinical and biological condition;

- Demonstration of granuloma without caseous necrosis;

- Exclusion of other granulomatosis [22].

- Systemic amyloidosis was retained before:

- Multisystemic clinical and paraclinical context;

- Amyloid deposits on at least an organ on histology.

- Systemic manifestations, during immunodeficiency, were retained before:

- Multisystemic clinical and paraclinical context;

- Primary or secondary immunodeficiency state;

- Absence of identifiable causes and/or mechanisms.

The approval of the local ethics committee was required.

\section{2) Exclusion criteria}

All incomplete medical records that did not allow data exploitation were excluded.

\section{3) Data collection and analysis}

The following data were collected: age, sex, diagnosis delay, the presence of prior monitoring, past medical history and comorbidities, clinical, biological, immunological and histological signs lead to conclude to the diagnostic. The diagnosis delay was defined by the duration between the onset of the first clinical manifestation and the date of diagnosis.

The data were recorded through an Excel file. Then, with R software, the Excel database was imported for variable recoding and analysis. The results were presented in text, table and graphical forms. 


\section{Results}

During the period of study, we gathered 962 medical records, 726 were included. It was 632 females and 94 males, that to say a ratio of 0.14 . The average age in our study was 43.76 years with extremes from 16 up to 86 years.

Seventy three (73) patients (10.03\%) had a family history of inflammatory rheumatism.

Around one third of our patients $(32.23 \%)$ had a prior monitoring. It was exclusively about a medical monitoring in $83 \%$ of our patients. Two-third of these patients had received only a symptomatic treatment (steroidal and/or non-steroidal anti-inflammatory), without any core therapy in their prior medical monitoring. $5 \%$ of the patients saw only traditional healers and $12 \%$ of the patients combined traditional treatment with medical treatment.

The mean diagnostic delay duration was 41.52 months (3.46 years). Table 1 points out the distribution of systemic diseases during our study and Table 2 shows the diagnostic time-limit of each systemic condition.

Table 1. Distribution of inflammatory systemic diseases in our study.

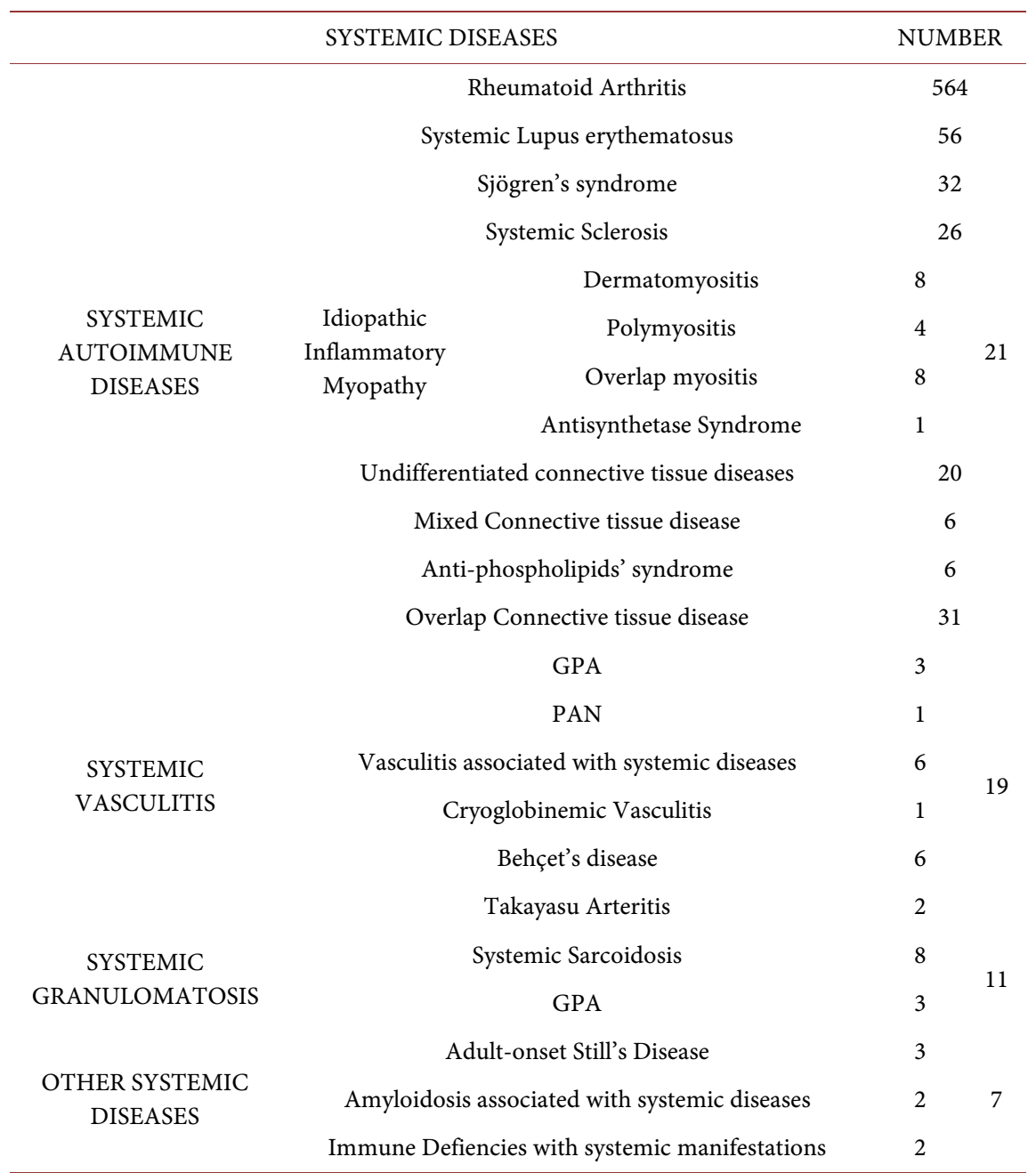

GPA: Granulomatosis with Polyangiitis PAN: Polyarteritis Nodosa. 
Table 2. Diagnostic delay of systemic diseases in our study.

\begin{tabular}{cc}
\hline Systemic Diseases & $\begin{array}{c}\text { Time from to symptoms-onset to diagnosis, } \\
\text { mean range, in years (month) }\end{array}$ \\
\hline All systemic diseases & $3.46(41.52)$ \\
Systemic Lupus erythematosus & $1.6(19.2)$ \\
Rheumatoid Arthritis & $3.8(45.6)$ \\
Sjögren's Syndrome & $3.16(37.92)$ \\
Mixed connective tissue diseases & $1(12)$ \\
Idiopathic Inflammatory Myopathy & $0.57(6.84)$ \\
Undifferentiated Connective tissue disease & $2.875(34.5)$ \\
Systemic Vasculitis & $6.6(79.2)$ \\
Systemic Sarcoïdosis & $2(24)$ \\
\hline
\end{tabular}

Five hundred and sixty four (564) patients were suffering of rheumatoid arthritis (RA) with an average age of 45 years and a sex ratio of 0.13 . In $84 \%$ of cases, the RA diagnostic was carried out at the disease later stage certified by the existence of articular erosions and deformities. Extra-articular manifestations of RA are summarized on Figure 1. A disease high activity with a Disease activity score (DAS) 28 (>5.1) was noted on $43.23 \%$ of patients. Immunologically, rheumatoid factors were positive in $77.3 \%$ and anti-cyclic citrullinated peptide auto-antibodies (anti-CCP) in $96 \%$ of patients.

Systemic lupus erythematosus was documented on 56 patients with an average age of 33.6 years and a sex ratio of 0.056. Cutaneous and articular involvement appeared on $96.43 \%$ of patients, lupus nephritis on $51.2 \%$ of cases, serous involvement and neurolupus on respectively $33.9 \%$ and $12.5 \%$ of patients. The distribution of auto-antibodies was as follow: ANA (86.2\%), Anti DNA (41.38\%), Anti-Sm (77.5\%), anti U1RNP (67.5\%).

Sjögren's syndrome was retained on 32 patients, in half of cases, it was primitive. The average age was $44.83 \%$ years and the sex ratio 0.18 .

Twenty six patients (26) had Systemic Sclerosis. The average age was 36.54 years and the sex ratio 0.18 . It was a diffuse cutaneous systemic sclerosis in $50 \%$ of cases. Raynaud's syndrome was documented in $46.1 \%$ of patients.

Idiopathic Inflammatory myopathies concerned 21 patients with a sex ratio of 0.22 and an average age of 41.59 years. They were dominated by DM and overlapmyositis, anti-synthetase anti-Jo syndrome was documented on one patient. Other documented auto-immune diseases were represented by Mixed connective tissue disease (06 cases), anti-phospholipid antibodies syndrome (05 cases). Connective tissue diseases were undifferentiated on 20 patients. Table 3 sums up the average age and the sex ratio of each pathology.

The associations of autoimmune diseases (AID) were documented on 41 patients in our study. It was an association of at least 02 connective tissue diseases (CTD) or "overlap CTD" on 31 patients. The entity of multiple auto-immune syndrome was retained on 07 patients. 


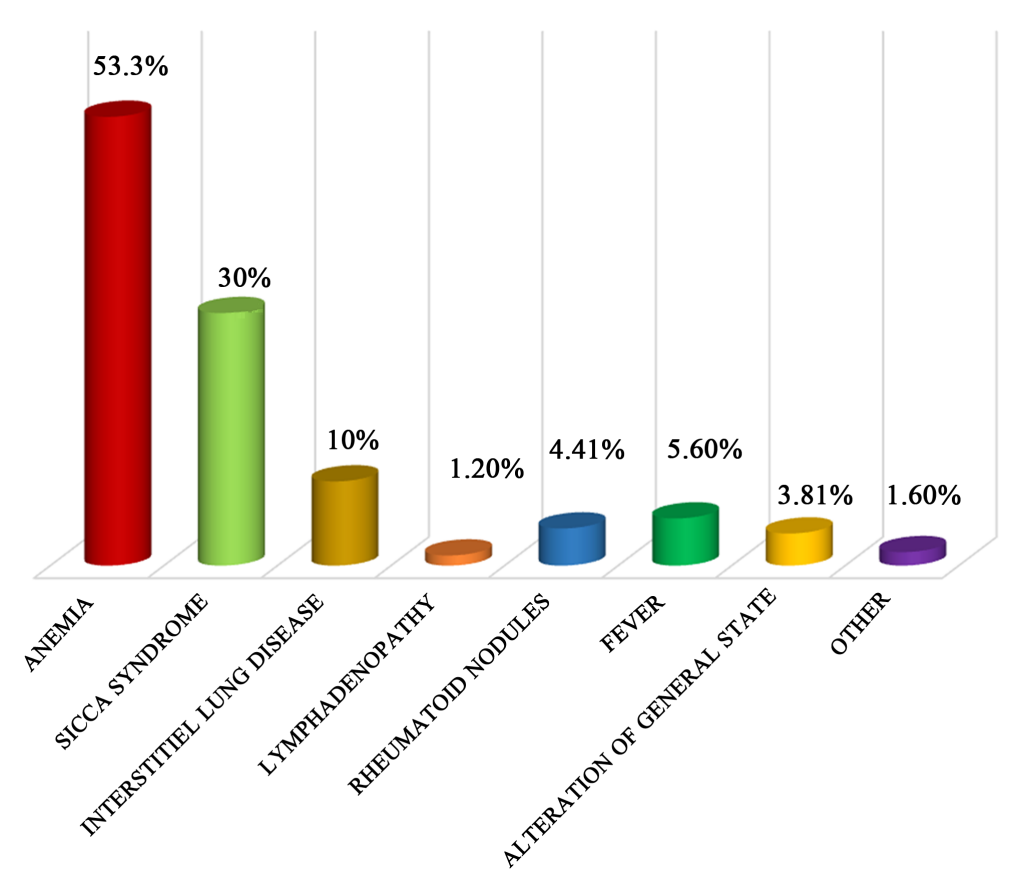

Figure 1. Extra-articular manifestations on rheumatoid arthritis.

Table 3. Distribution of sex-ratio and Mean age in our study.

\begin{tabular}{ccc}
\hline Systemic Diseases & Sex-Ratio & Mean age (years) \\
\hline All Systemic Diseases & 0.14 & 43.76 \\
Rheumatoid Arthritis & 0.13 & 45.06 \\
Systemic Lupus & 0.056 & 33.65 \\
Sjögren's Syndrome & 0.18 & 44.83 \\
Systemic sclerosis & 0.18 & 36.54 \\
Inflammatory Myopathy & 0.22 & 41.59 \\
Systemic Vasculitis & 0.9 & 35.95 \\
Undifferenciated CTD & 0.12 & 36.95 \\
Systemic Sarcoidosis & 0.33 & 60.25 \\
Mixed CTD & $0 / 6$ & 49.33 \\
Adult-onset Still's Disease & 0.66 & 37.67 \\
APLS & 0.25 & 33 \\
\hline
\end{tabular}

CTD: Connective Tissue Disease APLS: Anti Phospholipid’s Syndrome.

A diagnostic of systemic vasculitis was retained on 19 patients dominated by vasculitis secondary to systemic diseases (see Figure 2 about a case of rheumatoid vasculitis) and Behçet's disease.

The other systemic conditions was represented by systemic sarcoidosis (8 cases), Adult-onset Still's disease (3 cases), Systemic amyloidosis (2 cases) secondary to RA and sarcoidosis and 2 cases of systemic manifestations secondary to immune deficiency.

The comorbidities in our patients are summarized on the Table 4. High blood pressure was documented on 50 patients $(6.9 \%)$ and diabetes on 34 patients 


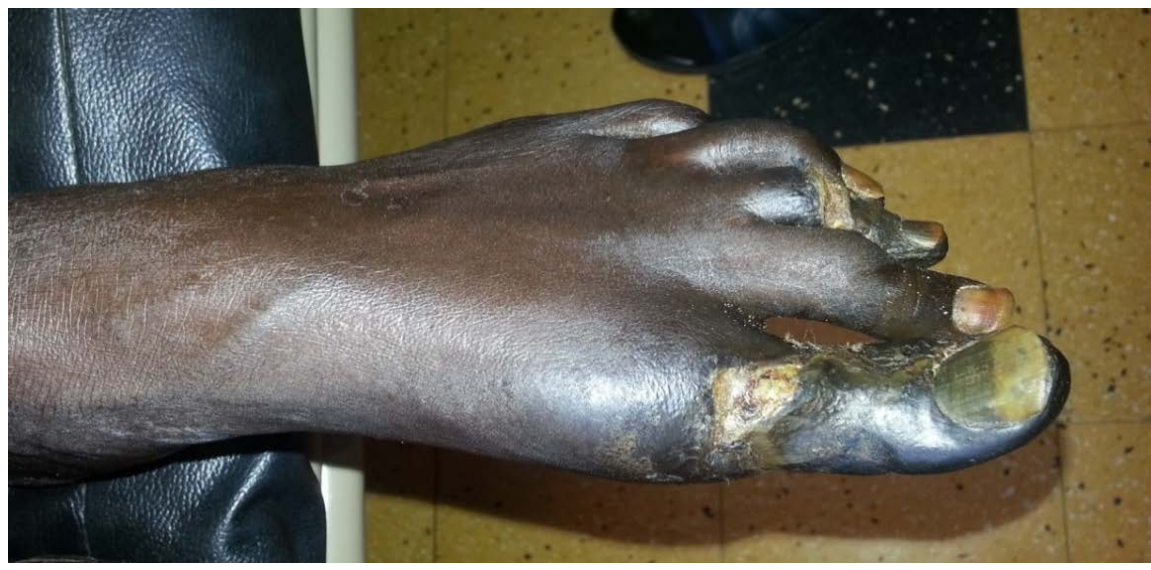

Figure 2. Digital necrosis during vasculitis secondary to rheumatoid arthritis.

Table 4. Distribution of comorbidities in our patients.

\begin{tabular}{ccc}
\hline Antecedents and Comorbidities & \multicolumn{3}{c}{$\mathrm{N}(\%)$} \\
\hline Familial history of inflammatory RD & 73 & $(10.06 \%)$ \\
Hypertension & 50 & $(6.9 \%)$ \\
Diabetes & 34 & $(4.6 \%)$ \\
Active Tabacco intoxication & 13 & $(1.7 \%)$ \\
Tuberculosis & 10 & $(1.38 \%)$ \\
Hepatitis B & 27 & $(3.7 \%)$ \\
Other & 6 & $(0.08 \%)$ \\
\hline
\end{tabular}

RD: Rheumatic Diseases.

(4.6\%). Tuberculosis and systemic diseases were associated on 10 patients $(1.38 \%)$. Table 4 sums up the antecedents and comorbidities in our series.

\section{Discussion}

We reported series of 726 patients in a 10 years study period. This multicentric study allowed a complete recruitment, including all Internal Medicine Departments of Dakar hospitals. However, Internal Medicine units do not have the monopoly of systemic diseases recruitment. These affections may be seen, according to their clinical phenotypes in other medical departments. This was a limitation of our study.

Other series of systemic auto-immune diseases were reported in Sub-Saharan Africa. Forty two (42) patients were chosen during 5 years at Ouagadougou [5]. In this study, systemic sclerosis predominated, followed up by lupus disease [5]. Down Togo and Abidjan, it was about respectively 84 and 44 patients, with RA as predominant affection [2] [6]. A more recent series in Togo helped to identify 626 cases of inflammatory rheumatism and connective tissue diseases in a period of 16years [7].

The average age in our study was 43.76 years and around two-third of our pa- 
tients $(63.2 \%)$ were part of the 30 - 60 years age group. Therefore, these affections would touch the more active populations, besides their functional impact, this would indicate their economic value by the direct and indirect costs of their management [4].

Female predominance was neat in our study, in accordance with the different African studies on systemic diseases [2] [3] [4] [23] [24] [25] [26] [27].

A prior follow-up was noticed on around $1 / 3$ of our patients. The use of traditional medicine represented a particularity in our study and would partially mean the ignorance of these affections by our populations and the weight of traditional beliefs in our regions. In the systemic auto-immune diseases sub-group, we confirmed RA predominance, in accordance with the literature data [3] [4].

Lupus on black people, likewise in our study, was remarkable by a relatively high prevalence of renal impairment, serositis and anti-Sm antibodies [27] [28] [29].

Idiopathic Inflammatory myopathies, Mixed connective tissue disease and APS had a lower incidence than other connective tissue diseases in our study and the African literature [3] [30].

Vasculitis are rarely reported, probably under-estimated in black Africa, we gathered 19 cases of them [31] [32].

Secondary vasculitis due to connective tissue diseases and Behçet disease predominated in our study. Only one case of PAN was reported in our series and the one from Ndongo and coll, that seems like to confirm the paradox between hepatitis Bendemicity in our regions and the rareness of reported cases of PAN associated with hepatitis B virus in African literature [32].

Belated diagnostic during systemic diseases was confirmed in our study by 41.52 months (3.46 years) average diagnostic time-limit. RA is the condition for which the existence of an interest of an early and "open window" therapy was more documented. The average age of diagnosis of RA was 45.6 months (3.8 years) in our study, 54 months in Ngongo's study, 78 months according to Niasse and 114 months (9.5 years) in Bileckot's study [23] [33] [34].

Belated diagnostic during systemic diseases would be linked to the lack of knowledge of these affections, the existence of particular way as the use of traditional medicine, the lack of specialists and the high cost of means of explorations in our areas. The association Tuberculosis-Systemic disease was recorded in 10 patients in our study (1.38\%). It was rarely reported in African literature despite the endemicity of tuberculosis in our areas and the predisposing terrain of systemic diseases [35]. However it should be taken as a matter of concern especially with the advent of biological therapies.

\section{Conclusion}

Systemic diseases in our study are characterized by their diversity, the predominance of rheumatoid arthritis and their belated diagnosis. Improving diagnostic procedures will help to cover systemic diseases in Africa. 


\section{Conflicts of Interest}

The authors have nothing to disclose.

\section{References}

[1] Combe, B. (2007) From Autoimmune Diseases to IMID and Autoinflammaory Syndromes. Revue du Rhumatisme, 74, 711-713.

https://doi.org/10.1016/j.rhum.2007.06.004

[2] Mijiyawa, M., Amanga, K., Oniankitan, I., Pitché, P. and Tchangaï-Wala, K. (1999) Connective Tissue Diseases in the Hospital Outpatient Service in Lomé (Togo). La Revue de Médecine Interne, 20, 13-17. https://doi.org/10.1016/S0248-8663(99)83004-5

[3] Adelowo, O.O. and Bello, M.K.N. (2014) Systemic Autoimmune Diseases: Not So Rare in Black Africans. Rheumatology (Sunnyvale), 4, 130. https://doi.org/10.4172/2161-1149.1000130

[4] Ouédraogo, D.-D., Ntisaba, H., Zabsonré-Tiendrébéogo, J., Tiéno, H., Bokossa, L.I.F., Kaboré, F. and Drabo, J. (2014) Clinical Spectrum of Rheumatic Diseases in a Department of Rheumatology in Ouagadougou (Burkina Faso). Clinical Rheumatology, 33, 385-389. https://doi.org/10.1007/s10067-013-2455-4

[5] Ouédraogo, D.D., Korsaga-Somé, N., Zabsonné Tiendrébéogo, J., Tiéno, H., Kaboré, H., Niamba, P. and Drabo, J. (2014) Connective Tissue Diseases in Hospital Practice in Ouagadougou (Burkina Faso). Medecine et Sante Tropicales, 24, 271-274.

[6] Eti, E., Yapi, I.D., Ouali, B., et al. (2004) Inflammatory Rheumatic Diseases at Cocody University Medical Center (Abidjan) from March 1998 to March 2000. Revue du Rhumatisme, 71, 1215-1220.

[7] Houzou, P., Oniankitan, O., Kakpovi, K., Koffi-Tessio, V.E., Tagbor, K.C., Fianyo, E. and Mijiyawa, M. (2013) Rheumatic Diseases Profile of 13517 West African Patients. La Tunisie méDicale, 91, 16-20.

[8] Liao, K.P., Batra, K.L., Chibnik, L., Schur, P.H. and Costenbader, K.H. (2014) Anti-Cyclic Citrullinated Peptide Revised Criteria for the Classification of Rheumatoid Arthritis. Annals of the Rheumatic Diseases, 67, 1557-1561.

https://doi.org/10.1136/ard.2007.082339

[9] Meyer, O. (2010) Systemic Lupus Erythematosus and Antiphospholipid Syndrome. Diagnostic and Follow-Up Criteria. Revue du Rhumatisme Monographies, 77, 82-88.

[10] Vitali, C., Bombardieri, S., Jonnson, R., et al. (2002) Classification Criteria for Sjögren's Syndrome: A Revised Version of the European Criteria Proposed by the American-European Consensus Group. Annals of the Rheumatic Diseases, 61, 554-558. https://doi.org/10.1136/ard.61.6.554

[11] Van den Hoogen, F., Khanna, D., Fransen, J., Johnson, S.R., et al. (2013) 2013 Classification Criteria for Systemic Sclerosis: An American College of Rheumatology/ European League against Rheumatism Collaborative Initiative. Arthritis Rheumatism, 65, 2737. https://doi.org/10.1002/art.38098

[12] Guis, S., Mattei, J.-P., Figarella-Branger, D. and Bendahan, D. (2010) Classification and Criteria of Idiopathic Inflammatory. Revue du Rhumatisme Monographies, 77, 99-102. https://doi.org/10.1016/j.monrhu.2010.01.011

[13] Hoogendijk, J.E., Amato, A.A., Lecky, B.R., et al. (2004) 119th ENMC International Workshop: Trial Design in Adult Idiopathic Inflammatory Myopathies, with the 
Exception of Inclusion Body Myositis. The Netherlands. Neuromuscular Disorders, 14, 337-345. https://doi.org/10.1016/j.nmd.2004.02.006

[14] Hayem, G. (2008) Mixed Connective Tissue Disease. In: Guillevin, L., Meyer, O. and Sibilia, J., Eds., Maladies et Syndromes Systémiques, 5ème éd, Flammarion Médecine Sciences, Paris, 516-531.

[15] Fautrel, B., Zinc, E., Golmard, J.L., Le Moel, G., et al. (2002) Proposal for a New Set of Classification Criteria for Adult-Onset Still Disease. Medicine, 81, 194-200. https://doi.org/10.1097/00005792-200205000-00003

[16] Jennette, J.C., Falk, R.J., Bacon, P.A., et al. (2012) Revisited International Chapel Hill Consensus Conference Nomenclature of Vasculitides. Arthritis \& Rheumatology, 65, 1-11. https://doi.org/10.1002/art.37715

[17] Leavitt, R.Y., Fauci, A.S., Bloch, D.A., Michel, B.A., Hunder, G.G., Arend, W.P., Calabrese, L.H., Fries, J.F., Lie, J.T., Lightfoot, R.W., et al. (1990) The American College of Rheumatology 1990 Criteria for the Classification of Wegener's Granulomatosis. Arthritis \& Rheumatology, 33, 1101-1107.

https://doi.org/10.1002/art.1780330807

[18] Arend, W.P., Michel, B.A., Bloch, D.A., Hunder, G.G., Calabrese, L.H., Edworthy, S.M., Fauci, A.S., Leavitt, R.Y., Lie, J.T., Lightfoot, R.W., et al. (1990) The American College of Rheumatology 1990 Criteria for the Classification of Takayasu Arteritis. Arthritis \& Rheumatology, 33, 1129-1134. https://doi.org/10.1002/art.1780330811

[19] Lightfoot, R.W., Michel, B.A., Bloch, D.A., Hunder, G.G., Zvaifler, N.J., McShane, D.J., Arend, W.P., Calabrese, L.H., Leavitt, R.Y., Lie, J.T., et al. (1990) The American College of Rheumatology 1990 Criteria for the Classification of Polyarteritis Nodosa. Arthritis \& Rheumatology, 33, 1088-1093.

https://doi.org/10.1002/art.1780330805

[20] Davatchi, F., Assaad-Khalil, S., Calamia, K.T., Crook, J.E., et al. (2014) The International Criteria for Behçet's Disease (ICBD), a Collaborative Study of 27 Countries on the Sensitivity and Specificity of the New Criteria. Journal of the European Academy of Dermatology and Venereology, 28, 338-347.

https://doi.org/10.1111/jdv.12107

[21] Danieli, M.G., Fraticelli, P., Franceschini, F., Cattaneo, R., et al. (1999) Five-Year Follow-Up of 165 Italian Patients with Undifferentiated Connective Tissue Diseases. Clinical and Experimental Rheumatology, 17, 585-591.

[22] Ben Abdelghani, K., Mahfoudhi, M., Hriz, A., et al. (2010) AA Amyloidosis Complicating Sarcoidosis: Two Cases and Literature Review. La Revue de Médecine Interne, 31, 369-371. https://doi.org/10.1016/j.revmed.2009.11.009

[23] Ndongo, S., Lekpa, F., Ka, M.M., et al. (2009) Presentation and Severity of Rheumatoid Arthritis at Diagnosis in Senegal. Rheumatology, 48, 1111-1113. https://doi.org/10.1093/rheumatology/kep178

[24] Fall, S., Pouye, A., Ndiaye, F.S., Ndongo, S., Leye, Y., Dioum, A., Dieng, M.T., Ka, E.F., Ka, M.M. and Moreira-Diop, T. (2011) Initial Presentation of Systemic Lupus Erythematosus in Senegal. Médecine d Afrique Noire, 58, 156-160.

[25] Diallo, M., Fall, A.K., Diallo, I., et al. (2010) Dermatomyositis and Polymyositis: 21 Cases in Sénégal. Médecine Tropicale, 70, 166-168.

[26] Dia, D., Dieng, M.T., Sy, T.N., et al. (2003) Systemic Scleroderma: 92 Cases in Dakar. Dakar Médical, 48, 82-86.

[27] Meyer, O. (2002) Systemic Lupus in Non-Caucasian Individuals. Revue du Rhumatisme, 69, 801-808. https://doi.org/10.1016/S1169-8330(02)00385-X 
[28] Adelowo, O.O., Ojo, O. and Oduenyi, I. (2012) Auto Antibodies in Nigerian Lupus Patients. African Journal of Medicine and Medical Sciences, 41, 177-181.

[29] Gbané-Koné, M., Ouattara, B., Djaha, K.J.M., Megne, E., Ngandeu, A.N., Coulibaly, A.K., Eti, E. and Kouakou, M.N. (2015) Autoantibodies in Systemic Lupus Erythematosus, on Black African Subject, in Abidjan. Open Journal of Rheumatology and Autoimmune Diseases, 5, 28-35. https://doi.org/10.4236/ojra.2015.52006

[30] Missounga, L., Iba Ba, J., Nseng Nseng Ondo, I.R., Madjinou, M.I.C.N., Malekou, D., Mouloungui, E.G.M., Nzengue, E.E., Boguikouma, J.B. and Kombila, M. (2017) Mixed Connective Tissue Disease: Prevalence and Clinical Characteristics in African Black, Study of 7 Cases in Gabon and Review of the Literature. Pan African Medical Journal, 27, 162.

[31] Jeandel, P. and Roux, H. (2002) Epidemiology of Rheumatic Diseases in Africa South of the Sahara. Revue du Rhumatisme, 69, 764-776.

https://doi.org/10.1016/S1169-8330(02)00389-7

[32] Ndongo, S., Diallo, S., Tiendrebeogo, J., Diop, I.B., Tall, A., Pouye, A., Ka, M.M. and Diop, T.M. (2010) Systemic Vasculitis: Study of 27 Cases in Senegal. Médecine Tropicale, 70, 264-266.

[33] Niasse, M., Kane, B.S., Ndiaye, A.A., Ndao, A.C., Djiba, B., Diack, N.B., Sall, F.B., Ndour, M.A., Diagne, N., Faye, A., Fall, B.C., Ndongo, S. and Pouye, A. (2017) Severity of the Rheumatoid Arthritis in Sub-Saharan Africa: Study of 403 Senegalese Observations. Open Journal of Internal Medicine, 7, 151-159. https://doi.org/10.4236/ojim.2017.74016

[34] Bileckot, R. and Malonga, A.C. (1998) Rheumatoid Arthritis in Congo-Brazzaville. A Study of Thirty-Six Cases. Revue du Rhumatisme, 65, 308-312.

[35] Diallo, S., Ndongo, S. and Leye, A. (2009) Tuberculosis and Systemic Diseases. Médecine Tropicale, 69, 307-308. 